\title{
American Academy of Neurology Telehealth Position Statement
}

Jaime M. Hatcher-Martin, MD, PhD, Neil A. Busis, MD, Bruce H. Cohen, MD, Rebecca A. Wolf, MBA, Elaine C. Jones, MD, Eric R. Anderson, MD, PhD, Joseph V. Fritz, PhD, Steven J. Shook, MD, MBA, and Riley M. Bove, MD, MMSc

Neurology ${ }^{\circledR}$ 2021;97:334-339. doi:10.1212/WNL.0000000000012185

\author{
Correspondence \\ Ms. Wolf \\ practice@aan.com
}

\begin{abstract}
Telehealth services complement in-person neurologic care. The American Academy of Neurology supports patient access to telehealth services regardless of location, coverage for telehealth services by all subscriber benefits and insurance, equitable provider reimbursement, simplified state licensing requirements easing access to virtual care, and expanding telehealth research and quality initiatives. The roles and responsibilities of providers should be clearly delineated in telehealth service models.
\end{abstract}

\section{Introduction}

The American Academy of Neurology (AAN) is the world's largest neurology specialty society, representing more than 36,000 neurologists and clinical neuroscience professionals. The AAN is dedicated to promoting the highest quality patient-centered neurologic care. This update to the 2014 AAN position statement on telemedicine ${ }^{1}$ reflects recent advances in telehealth practice and research and changes in related regulations, policies, and legislation. ${ }^{2-4}$ The AAN advocates for policies that ease unnecessary restrictions to virtual care, offers guidance about the clinical practice of telehealth, and identifies important gaps in the telehealth knowledge base. To ensure delivery of safe, high-quality virtual care, stakeholders, including providers (defined in this article as neurologists and other qualified health care professionals who provide neurologic services), regulators, policymakers, and payers, need to consider access, standards, reimbursement, practicing across state borders, professional liability, and coordination of patient care with local providers.

\section{Definition of Telehealth}

Telehealth, also known as virtual care, uses digital information and telecommunication technologies to provide health care when participants are separated by distance or time. Participants include physicians, other qualified health care professionals, and additional members of the health care team connected virtually with patients, family members, and other care providers. Telehealth facilitates the exchange and interpretation of text, data, images, audio, or video, with synchronous (e.g., provider and patient available at the same time) or asynchronous communication. Examples of telehealth services include real-time 2-way interactive audio-video conferencing, mobile health applications, store-and-forward evaluation and management services, virtual check-ins, electronic interprofessional consultations, telephone services, and remote patient monitoring. The choice of telehealth modality for a specific virtual encounter is determined by the needs of the patient, their ability to access and use the necessary technology, the legal and regulatory landscapes, and the available supporting evidence.

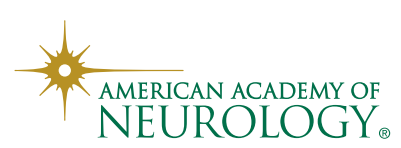

From SOC Telemed (J.M.H.-M., E.C.J., E.R.A.), Reston, VA; NYU Langone Health (N.A.B.), New York, NY; Akron Children's Hospital (B.H.C.), OH; American Academy of Neurology (R.A.W.), Minneapolis, MN; Corticare (E.R.A.), Carlsbad, CA; Intensive Neuro (E.R.A.), St. Petersburg, FL; Dent Neurologic Institute (J.V.F.), Amherst, NY; Neurological Institute (S.J.S.), Cleveland Clinic, $\mathrm{OH}$; and University of California (R.M.B.), San Francisco.

Go to Neurology.org/N for full disclosures. Funding information and disclosures deemed relevant by the authors, if any, are provided at the end of the article.

Approved by the Practice Management and Technology and Health Policy Subcommittees on November 17, 2020; by the Medical Economics and Practice Committee on November 25, 2020; and by the AAN Institute Board of Directors on December 11, 2020. 


\section{Glossary}

AAN = American Academy of Neurology; IMLC = Interstate Medical Licensure Compact.

\section{Benefits of Telehealth}

Telehealth can benefit patients and providers. Examples include:

- Improved access to expert neurologic evaluation ${ }^{5}$

- Enhanced comfort, convenience, and safety, particularly for patients with limited mobility due to their medical condition $^{6}$ or need for home medical support equipment ${ }^{7}$

- Reduced travel time and associated costs ${ }^{5}$

- Decreased time away from work or other essential activities for patients and care partners ${ }^{8}$

- Reduced caregiver stress ${ }^{9}$

- Increased care partner and provider participation during a visit ${ }^{9}$

- Better assessment of social determinants of health, including the patient's home environment ${ }^{10}$

- Early intervention prior to a scheduled office visit, based on continuous assessment of neurologic disease progression and treatment efficacy ${ }^{11}$

- Protection of patient and providers from infectious disease exposure and reducing use of personal protective equipment ${ }^{4}$

Evidence supports the effectiveness of telehealth in inpatient and outpatient settings, for acute evaluation and routine assessment ${ }^{5,12}$ and for multiple neurologic subspecialties. ${ }^{5,13}$ During the early part of the coronavirus disease 2019 (COVID-19) pandemic in 2020, neurology practices had one of the highest uptake rates for ambulatory telemedicine ( $47.9 \%$ of total visits) and a smaller decline in total visits when compared with other specialties. ${ }^{14}$ In acute emergency department or inpatient hospital settings, patients may be assessed and rapidly triaged to determine whether they would be best served at their current location or transferred to another facility. This benefits patients by allowing them to remain in their communities when possible and expedites access to advanced services when appropriate, thus optimizing resource utilization.

Video visits have proven to be cost-effective. ${ }^{15,16}$ However, they do not necessarily reduce the practice expenses incurred in delivering care compared to in-person visits because of needs for technical infrastructure and support, security and privacy measures, patient education and logistics, and a potentially wide range of central and remote office and hospital network collaborations among essentially every node of patient care. A thorough analysis of the practice expense must be a focus of investigation.

\section{Potential Solutions for Barriers to Telehealth}

\section{Access}

Patients should have access to high-quality telehealth services in the United States and its territories and when traveling abroad. Initially, telehealth programs were focused on patients living in rural settings with no access to specialized ambulatory and inpatient health care services. However, many other patients also have barriers to health care access, including those (1) who live in nursing homes and rehabilitation facilities; (2) with conditions that make travel excessively burdensome; (3) who are unable to drive; (4) who live in remote military settings; (5) who live in densely populated urban areas where traveling even short distances can be timeconsuming or expensive; (6) whose safety would be compromised by in-person visits (e.g., at risk for infection or with a need for home medical support equipment); and (7) who seek to improve continuity of care when they are traveling (including those who may spend several months of the year at another residence).

Telehealth should be an option for both new-to-practice and established ambulatory patients provided they are appropriately triaged to the visit type that meets their unique needs. In addition, care gaps affecting patients admitted to hospitals with no neurologic consultation coverage could be addressed by expanding inpatient teleneurology services.

One potential benefit of expanding telehealth as a national model of health care is improving convenience and democratizing access to expert subspecialists throughout the nation. However, an unintended consequence could be negatively affecting the sustainability of local practices that currently offer the benefits of in-person and long-term continuity of care. Furthermore, without the provider understanding community social and medical resources and local rules (such as driving restriction rules), the remotely practicing provider may be delivering care with significant gaps. Further investigation is required to address this paradox.

The AAN encourages actions to minimize the digital divide by supporting affordable nationwide high-speed Internet access to limit disenfranchisement of those with inadequate or unaffordable network connectivity and efforts to promote digital literacy and alleviate other technology or device limitations. Because some patients have barriers related to language and visual or hearing impairments, resources to assist with translator services and appropriate, easily accessed adaptive technology must be available and reimbursed at equitable rates. Telephone-only visits should be available for encounters that require real-time two-way interaction but in which an audio-video encounter may not be necessary, e.g., medication reconciliation, some counseling situations, discussion of treatment side effects, or when patients do not have or cannot use more advanced telehealth modalities. 


\section{Reimbursement and Payment Parity}

The complexity of various coverage policies, service and procedure codes, reimbursement rates, and documentation standards across Medicare, Medicaid, and numerous private payers creates important barriers to providers trying to incorporate telehealth services into their practices. The definition of "parity" varies by state and insurer. Moreover, the cost borne by the patient is difficult to determine in advance of the provision of services. Reform should be based on the following principles:

- Patient financial responsibility (e.g., fees and copays) for telehealth encounters should not exceed comparable inperson expenses.

- Coverage and the professional component of reimbursement for two-way real-time interactive encounters should be independent of setting (in-person, audio-video, telephone), provided that standards of care for the encounters are met, because the provider's cognitive work is equivalent.

- The practice expense of providing a two-way real-time interactive telehealth service may be different from that of providing an in-person service and should be determined by evidence- and resource-based methodologies.

- Professional and practice expense reimbursement for providing other telehealth modalities such as store-andforward digital evaluation and management services, interprofessional consultations, and remote physiologic monitoring should be evidence- and resource-based.

- To best address the needs of the patient and their health, the appropriateness of a telehealth evaluation should be determined on a case-by-case basis by the provider and the patient, not by the payer.

- When traveling out of state, patients should have coverage for telehealth access to their home state providers.

- If there are no local providers practicing a certain specialty, patients should have telehealth access covered for that specialty.

- Policies should support and encourage the development of telehealth care models in addition to audio-video encounters that can potentially improve patient outcomes and reduce costs. Examples may include remote monitoring and asynchronous evaluation and management services.

- In addition to fee-for-service reimbursement models, value-based telehealth models should be developed to optimize health care resource utilization at multiple levels: insurance, practice, patient, and society.

\section{Telehealth Practice Across State Borders}

Each state defines and regulates the practice of medicine, including telehealth, within its boundaries. State regulations dictate what constitutes a physician-patient relationship, what services are permissible once a relationship is established, if and what medications can be prescribed, scope of practice, and malpractice policies. ${ }^{17}$ These variations pose significant barriers to the practice of telehealth across state borders. Licensing, prescribing, and related policies should be simplified.
A desirable solution could include blanket reciprocity and an expedited licensing process that would require one unrestricted state license, a new background check for each state in which telemedicine is practiced, and reduced annual fees for limited practices. This would ensure protection of patients' rights to receive telehealth services as they require. The Interstate Medical Licensure Compact (IMLC), an agreement among 29 participating US states, the District of Columbia, and Territory of Guam to streamline the state licensing process for physicians who qualify, maintains the state's authority to regulate the practice of medicine within its borders. Whereas the IMLC simplifies the application process, it does not standardize practice requirements.

Medical liability for telehealth services varies from carrier to carrier. Unless this changes, neurologists must understand individual carrier policies to ensure that telehealth encounters are covered by their policy and apply to the states in which their patients are located.

\section{Hospital Credentialing}

Hospital credentialing requirements and procedures vary between hospitals. This complex process can delay patient access to needed care. Simplification of hospital credentialing requirements and widespread utilization of certified credentials verification organizations would improve patient access to inpatient teleneurology services.

\section{Streamlining Other Telehealth Processes}

Currently there is considerable variability across payers, sites of service, and health care organizations regarding the need and type of consent required prior to a telehealth encounter, requirements for billing compliance, and the necessity for an in-person encounter prior to a virtual encounter. Barriers to practicing telehealth would be decreased if these processes were simplified or standardized.

\section{Delineation of Roles and Responsibilities}

To prevent confusion and maximize quality and safety of the telehealth care provided, the roles and responsibilities of participating facilities, clinicians (including, but not limited to, physicians, advanced practice providers, nurses, and trainees), and hospital and practice staff should be clearly delineated. In view of the limitations of telehealth (e.g., requiring nuanced or detailed neuromuscular, ophthalmologic, and vestibular examinations), the medical community should practice responsible behavior regarding appropriate remote evaluation in instances where the lack of an in-person examination may compromise medical decision-making. It is also helpful to clarify the expected nature and duration of the therapeutic relationship, including the relationship between a consultant seen via telehealth for a second opinion relative to the patient's usual care team and expected follow-up if the provider is prescribing medications or suggesting diagnostic testing.

In instances in which telehealth services are provided to a remote clinic or hospital, the AAN agrees with the American College of Emergency Physicians that "the best patient care occurs when 
there is no ambiguity as to which provider is responsible for care of a patient." ${ }^{\prime 18}$ Agreements between local and remote sites need strict clarification of respective roles prior to initiating patient care. This includes, but is not limited to, the scheduled availability of the telehealth provider; who is responsible for placing orders, following up test results, and assessing the patient after consultation; billing responsibilities; and IT support.

\section{Limitations of Telehealth Services}

\section{Adequacy of Telehealth Evaluations}

As telehealth becomes more commonplace, including telehealth encounters with patients in their homes, it is important that patients and consumers understand the benefits, limitations, and their rights regarding these services. The ability to effectively triage new patients and concerns via telehealth has not been wellstudied. Although telehealth can be used to evaluate new patients or new symptoms, it may be difficult to determine whether the appropriate assessment and medical decision-making can be adequately performed via telehealth. Patients and referring health care providers should be informed of the possibility that patients may still need to seek in-person care if their concerns cannot be safely addressed via telehealth. In addition, a provider may lack knowledge about, and availability of, social and medical resources near the patient. National initiatives to educate patients and provide standard language regarding the use of telehealth can help inform and protect patients and providers.

\section{Cost}

The initial economic investment to establish a telehealth practice may be a limitation for some practices and is based on the settings where telehealth will be provided; the proportion of the practice consisting of telehealth; necessary staff to help with setting up, scheduling, triaging, and greeting the patient during the telehealth visit prior to the provider connecting to the visit; coding; and billing. Additional expenses potentially include the cost of the platform used and hardware such as computers, tablets, carts, or accessories such as microphones and cameras at the provider and patient locations. In addition, the need for information technology support and new staff or training of existing staff are factors to be considered.

\section{Fraud}

Telehealth modalities can provide substantial benefits to patients, but these care models are potentially vulnerable to the same fraudulent practices that may occur with in-person evaluations. ${ }^{19}$ Payers are concerned the cost of care could increase if patients are asked to follow-up more often than necessary or that visits could be fabricated or billed at levels higher than warranted. Providers fear that these concerns may prompt regulators to inappropriately limit telehealth access or lead to a disproportionate cost of compliance for providers offering telehealth services. Data on billing behavior can help determine whether fraud or abuse has occurred, and the digital footprint of visits is traceable, thus reducing the risk of fabricated visits. The programs in place to monitor in-person activities will be adequate to monitor for telehealth fraud.

\section{Cybersecurity}

Telehealth expansion raises concerns for cybersecurity and risk of access to private patient information, malware infections, ransomware attacks, and system breaches. Although not specific to telehealth, these concerns must be considered and addressed given increased risk of compromise for practices that do not appropriately protect their systems.

\section{Research Gaps}

To expand the evidence base of telehealth, further research is needed spanning the spectrum of virtual health care delivery models including maximizing the value and quality of the encounter and minimizing the cost. Conversely, modifications to coverage, licensing, and liability policies will necessitate understanding the effect of these changes on access to telehealth care and on clinical practices, including community physicians.

Given the known marked racial, ethnic, and socioeconomic disparities in access to neurologic care and outcomes, ${ }^{20,21}$ we must better understand and address technological literacy and the digital divide ${ }^{8,22}$ as well as patient perspectives on quality, trust, privacy concerns if living in crowded living conditions, ${ }^{23}$ or regions with inadequate Internet bandwidth.

Optimal examination techniques for direct-to-patient telehealth, limitations of the current virtual neurologic examination and methods to work around them, and applications of technologyenhanced examination methods (e.g., biosensors or smartphonebased tasks) require further investigation. Assessment of patient functioning in the home can be enhanced with use of passive and smartphone-based sensors to permit unobtrusive remote patient monitoring and artificial intelligence algorithms to interpret these data. Understanding of the effect of telehealth visits on clinical outcomes, both short-term (e.g., types of concerns best assessed, diagnostic accuracy, indications for triage to in-person evaluations) and long-term (e.g., neurologic disability progression, quality of life), is needed. These clinical outcomes can be weighed against costs from patient, payer, clinical practice, and health system perspectives, and against the effect on care value. Research into optimal methods of graduate and postgraduate training in telehealth care is also needed.

\section{AAN Policy Guidance for Telehealth}

The AAN recommends that all stakeholders support the following:

- Advocating for the needs of our patients and members in legislative, regulatory, and payment policies that pertain to telehealth

- Promotion of telehealth services to improve access to care, patient satisfaction, and safety; enable providers to practice in care models that promote career satisfaction and wellbeing; and reduce health care costs 
- Determination of the appropriateness of a telehealth evaluation on a case-by-case basis by the provider and the patient to best protect the interests of the patient, not by payment policy

- Access to telehealth services for all patients located in any US state or territory, regardless of geographic location of the patient, provider, or payer

- Support and encouragement of the development of a variety of virtual care models with the potential to improve patient outcomes and reduce costs, including remote monitoring and asynchronous visits

- Payer coverage for translation and adaptive services for patients who speak a different language or are visually or hearing-impaired

- Payment parity for the professional component of twoway interactive real-time virtual services regardless of the method used (e.g., in-person, video, telephone) provided standards of care are met

- Evidence- and resource-based determination of practice expenses of telehealth services, which may be different from practice expenses for providing in-person services

- Resource-based valuation for reimbursement including provider work, practice expense, and liability insurance expenses for emerging communication-based technology services including audio-only encounters, store-and-forward digital evaluation and management services, interprofessional consultations, and remote physiologic monitoring

- Comparable patient financial responsibility (e.g., fees and copays) for telehealth encounters and in-person evaluations

- Understanding currently applicable state-specific laws regarding the practice of telehealth for each location in which patients are seen

- Simplified state medical licensing, prescribing, hospital credentialing, medical liability policies, insurance coverage, and reimbursement schedules for telehealth across state borders

- Unambiguous delineation of where responsibility of the teleneurologist ends and the local admitting or consulting physician's responsibilities begin for each telehealth encounter

- Appropriate remote evaluation in instances in which the lack of an in-person examination limits medical decisionmaking

- Support for further technological innovations to better enhance patient confidentiality and safety

- Research and development of virtual care models, including patient triage, which are cost-effective and expediently evaluate and manage patients in any setting remote from their provider

- Research on the benefits and limitations of telehealth, as well as its effect on health equity, including access to care for socioeconomically disadvantaged populations

- Development of optimal methods for graduate and postgraduate training in telehealth

The AAN predicts that telehealth will continue to play an essential role in the care of patients with neurologic conditions. We will best serve our patients and our members by advocating for increased access, broader insurance coverage, fair reimbursement, reduced regulatory and legislative barriers, and expanding the telehealth evidence base by promoting research on its proper roles and value in neurologic care and on the costs associated with providing telehealth services.

\section{Position Statement History}

Update drafted by Jaime M. Hatcher-Martin, MD, PhD; Neil A. Busis, MD; Bruce H. Cohen, MD; Rebecca A. Wolf, MBA; Elaine C. Jones, MD; Eric R. Anderson, MD, PhD; Joseph V. Fritz, PhD; Steven J. Shook, MD, MBA; and Riley M. Bove, $\mathrm{MD}, \mathrm{MMSc}$.

Original drafted by Vernice Bates, MD; Pushpa Narayanaswami, MBBS, MD; Sarah Song, MD; Jeffrey A. Switzer, DO; Jack W. Tsao MD, DPhil; and Tim Miller (AAN Staff).

\section{Study Funding}

The authors report no targeted funding.

\section{Disclosure}

J.M. Hatcher-Martin is employed by SOC Telemed, which is a teleneurology company; serves in a compensated role on a scientific advisory or data safety monitoring board for Acadia and Neurocrine; serves in a compensated role as a speaker and site reviewer with the National Parkinson Foundation; and has a noncompensated relationship as an advisory board member with Cerner that is relevant to AAN interests or activities. N.A. Busis serves as alternate CPT advisor for and has received personal compensation for speaking engagements from the AAN. B.H. Cohen serves as an associate editor for Continuum, Mitochondrion, and Pediatric Neurology; serves as the chair of the scientific and medical advisory board of the United Mitochondrial Disease Foundation; serves as a consultant for Minovia Therapeutics, Modis Therapeutics (Zogenix), NeuroVive Pharmaceutical AB, Reneo Pharmaceuticals, Inc., and the US Department of Health \& Human Services; serves as a CPT consultant for the AAN; receives research/grant support from BioElectron Technologies (PTC Therapeutics), the NIH (U54NS078059), and Stealth BioTherapeutics Inc. and publishing royalties from Elsevier; and has received personal compensation for speaking engagements from the AAN and Stealth BioTherapeutics Inc. R.A. Wolf is employed by the AAN and has an immediate family member who has received compensation for serving as an employee of Blue Cross Blue Shield of Minnesota. E.C. Jones is employed by SOC Telemed, which is a teleneurology company; and serves as Deputy Editor of Neurology ${ }^{\circledR}$ : Clinical Practice for the AAN. E.R. Anderson is employed by SOC Telemed and Corticare, which are teleneurology companies; and is the owner of Intensive Neuro, a medical consulting company. J.V. Fritz receives consulting support from McKesson Corporation, Biogen Pharmaceuticals, and Philips 
Healthcare; and is an owner in the consulting firm NeuroNetPro LLC. S.J. Shook reports no disclosures relevant to the manuscript. R.M. Bove has received research support from Akili Interactive, Biogen, and Roche Genentech; is a Harry Weaver Scholar of the National Multiple Sclerosis Society; has received research support from the UCSF Weill Institute for Neurosciences, Hilton Foundation, California Initiative to Advance Precision Medicine, and the Sherak Foundation; and received personal compensation for consulting from Alexion, Biogen, EMD Serono, Novartis, Roche Genentech, and Sanofi Genzyme. Go to Neurology.org/N for full disclosures.

\section{Publication History}

Received by Neurology January 5, 2021. Accepted in final form April 19, 2021.

\section{Appendix Authors}

\begin{tabular}{lll}
\hline Name & Location & Contribution \\
\hline Jaime M. & SOC Telemed, Reston, & $\begin{array}{l}\text { Concept, design, drafting, and } \\
\text { revising the manuscript, critical } \\
\text { Martin, MD, }\end{array}$ \\
PhD & & $\begin{array}{l}\text { revisions of the manuscript for } \\
\text { important intellectual content, } \\
\text { supervision including } \\
\text { responsibility for conduct and } \\
\text { final approval }\end{array}$ \\
&
\end{tabular}

\begin{tabular}{lll}
\hline $\begin{array}{l}\text { Neil A. Busis, } \\
\text { MD }\end{array}$ & $\begin{array}{l}\text { NYU Langone Health, } \\
\text { New York, NY }\end{array}$ & $\begin{array}{l}\text { Concept, design, drafting, } \\
\text { and revising the manuscript, } \\
\text { critical revisions of the } \\
\text { manuscript for important } \\
\text { intellectual content }\end{array}$ \\
\hline $\begin{array}{l}\text { Bruce H. } \\
\text { Cohen, MD }\end{array}$ & $\begin{array}{l}\text { Akron Children's } \\
\text { Hospital, OH }\end{array}$ & $\begin{array}{l}\text { Critical revisions of the } \\
\text { manuscript for important } \\
\text { intellectual content }\end{array}$ \\
\hline
\end{tabular}

\section{Rebecca A. American Academy of Concept, design, drafting, and} Wolf, MBA Neurology, revising the manuscript, Minneapolis, MN supervision including responsibility for conduct and final approval

Elaine C. Jones, SOC Telemed, Reston, Concept, design, drafting, MD VA and revising the manuscript, critical revisions of the manuscript for important intellectual content

\begin{tabular}{lll}
\hline Eric R. & SOC Telemed, Reston, & Concept, design, drafting, \\
Anderson, MD, VA & and revising the manuscript, \\
PhD & critical revisions of the \\
& manuscript for important \\
& intellectual content
\end{tabular}

Joseph V. Fritz, Dent Neurologic Concept, design, drafting, PhD Institute, Amherst, NY and revising the manuscript, critical revisions of the manuscript for important intellectual content
Appendix (continued)

\begin{tabular}{lll}
\hline Name & Location & Contribution \\
\hline $\begin{array}{l}\text { Steven J. } \\
\text { Shook, MD, } \\
\text { MBA }\end{array}$ & $\begin{array}{l}\text { Neurologic Institute, } \\
\text { Cleveland Clinic, OH }\end{array}$ & $\begin{array}{l}\text { Critical revisions of the } \\
\text { manuscript for important } \\
\text { intellectual content }\end{array}$ \\
\hline $\begin{array}{l}\text { Riley M. Bove, } \\
\text { MD, MMSc }\end{array}$ & $\begin{array}{l}\text { University of } \\
\text { California, San } \\
\text { Francisco }\end{array}$ & $\begin{array}{l}\text { Critical revisions of the } \\
\text { manuscript for important } \\
\text { intellectual content }\end{array}$ \\
\hline
\end{tabular}

\section{References}

1. American Academy of Neurology Position Statement. Telemedicine. American Academy of Neurology; 2014. Accessed March 8, 2021. Available at: aan.com/siteassets/home-page/ policy-and-guidelines/policy/position-statements/18 telemedicineps_v304.pdf.

2. Dorsey ER, Topol EJ. Telemedicine 2020 and the next decade. Lancet. 2020; 395(10227):859.

3. Hodgkins M, Barron M, Jevaji S, Lloyd S. Physician requirements for adoption of telehealth following the SARS-CoV-2 pandemic. NPJ Digital Med. 2021;4(11):19.

4. Koonin LM, Hoots B, Tsang CA, et al. Trends in the use of telehealth during the emergence of the COVID-19 pandemic: United States, January-March 2020. MMWR Morb Mortal Wkly Rep. 2020;69(43):1595-1599.

5. Hatcher-Martin JM, Adams JL, Anderson ER, et al. Telemedicine in neurology: Telemedicine Work Group of the American Academy of Neurology update. Neurology. 2020;94(1):30-38.

6. Dorsey ER, Venkataraman V, Grana MJ, et al. Randomized controlled clinical trial of "virtual house calls" for Parkinson disease. JAMA Neurol. 2013;70(5):565-570.

7. Muñoz-Bonet JI, López-Prats JL, Flor-Macián EM, et al. Usefulness of telemedicine for home ventilator-dependent children. J Telemed Telecare. 2020;26(4):207-215.

8. Bove R, Garcha P, Bevan CJ, Crabtree-Hartman E, Green AJ, Gelfand JM. Clinic to inhome telemedicine reduces barriers to care for patients with MS or other neuroimmunologic conditions. Neurol Neuroimmunol Neuroinflamm. 2018;5(6):e505.

9. Guzik AK, Switzer JA. Teleneurology is neurology. Neurology. 2020;94(1):16-17.

10. Wechsler LR. The teleneurology revolution. Ann Neurol. 2020;88(4):656-657.

11. Powers R, Etezadi-Amoli M, Arnold EM, et al. Smartwatch inertial sensors continuously monitor real-world motor fluctuations in Parkinson's disease. Sci Transl Med. 2021;13(579):eabd7865.

12. Meyer BC, Raman R, Ernstrom K, et al. Assessment of long-term outcomes for the STRokE DOC telemedicine trial. J Stroke Cerebrovasc Dis. 2012;21(4):259-264.

13. Hassan A, Mari Z, Gatto EM, et al. Global survey on telemedicine utilization for movement disorders during the COVID-19 pandemic. Mov Disord. 2020;35(10):1701-1711.

14. Patel SY, Mehrotra A, Huskamp HA, Uscher-Pines L, Ganguli I, Barnett ML. Variation in telemedicine use and outpatient care during the COVID-19 pandemic in the United States. Health Aff. 2021;40(12):349-358.

15. Demaerschalk BM, Switzer JA, Xie J, Fan L, Villa KF, Wu EQ. Cost utility of hub-andspoke telestroke networks from a societal perspective. Am J Manag Care. 2013; 19(12):976-985.

16. Reider-Demer M, Raja P, Martin N, Schwinger M, Babayan D. Prospective and retrospective study of videoconference telemedicine follow-up after elective neurosurgery: results of a pilot program. Neurosurg Rev. 2018;41(2):497-501.

17. Mehrotra A, Nimgaonkar A, Richman B. Telemedicine and medical licensure: potential paths for reform. N Engl J Med. 2021;384(8):687-690.

18. American College of Emergency Physicians (ACEP). Writing Admission and Transition Orders. ACEP Policy Statement 2017. Accessed March 8, 2021. acep.org/patientcare/policy-statements/writing-admission-and-transition-orders/.

19. Department of Justice (DOJ). National Health Care Fraud and Opioid Takedown Results in Charges Against 345 Defendants Responsible for More than $\$ 6$ Billion in Alleged Fraud Losses. United States Department of Justice; 2020. Accessed March 8, 2021. justice.gov/opa/pr/national-health-care-fraud-and-opioid-takedown-results-chargesagainst-345-defendants.

20. Amezcua L, McCauley JL. Race and ethnicity on MS presentation and disease course. Mult Scler. 2020;26(5):561-567.

21. Saadi A, Himmelstein DU, Woolhandler S, Mejia NI. Racial disparities in neurologic health care access and utilization in the United States. Neurology. 2017;88(24):2268-2275.

22. McGinley MP, Gales S, Rowles W, et al. Expanded access to multiple sclerosis teleneurology care following the COVID-19 pandemic. Mult Scler J Exp Transl Clin. 2021; 7(1):2055217321997467.

23. Brown EM. The Ontario Telemedicine Network: a case report. Telemed J E Health. 2013;19(5):373-376. 


\section{Neurology}

\section{American Academy of Neurology Telehealth Position Statement}

Jaime M. Hatcher-Martin, Neil A. Busis, Bruce H. Cohen, et al.

Neurology 2021;97;334-339 Published Online before print May 13, 2021

DOI 10.1212/WNL.0000000000012185

\section{This information is current as of May 13, 2021}

\section{Updated Information \&} Services

\section{References}

Subspecialty Collections

Permissions \& Licensing

Reprints including high resolution figures, can be found at: http://n.neurology.org/content/97/7/334.full

This article cites 20 articles, 5 of which you can access for free at: http://n.neurology.org/content/97/7/334.full\#ref-list-1

This article, along with others on similar topics, appears in the following collection(s):

Advocacy

http://n.neurology.org/cgi/collection/advocacy

Information about reproducing this article in parts (figures,tables) or in its entirety can be found online at:

http://www.neurology.org/about/about_the_journal\#permissions http://n.neurology.org/subscribers/advertise

Neurology ${ }^{\circledR}$ is the official journal of the American Academy of Neurology. Published continuously since 1951, it is now a weekly with 48 issues per year. Copyright @ 2021 American Academy of Neurology. All rights reserved. Print ISSN: 0028-3878. Online ISSN: 1526-632X.

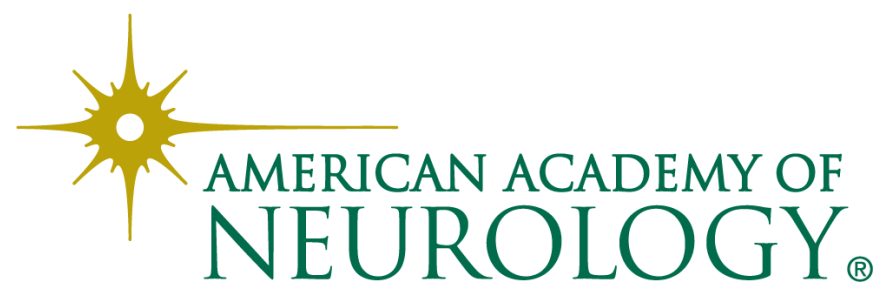

